(2) Open Access Full Text Article

\title{
Postural pattern recognition in children with unilateral cerebral palsy
}

This article was published in the following Dove Press journal:

Therapeutics and Clinical Risk Management

17 February 2014

Number of times this article has been viewed

\section{Małgorzata Domagalska- Szopa \\ Andrzej Szopa}

School of Health Sciences, Medical University of Silesia, Katowice, Poland
Background: Several different strategies for maintaining upright standing posture in children with cerebral palsy (CP) were observed.

Purpose: The purpose of the present study was to define two different postural patterns in children with unilateral CP, using moiré topography (MT) parameters. Additionally, another focus of this article was to outline some implications for managing physiotherapy in children with hemiplegia.

Patients and methods: The study included 45 outpatients with unilateral CP. MT examinations were performed using a CQ Elektronik System device. In addition, a weight distribution analysis on the base of support between unaffected and affected body sides was performed simultaneously. A force plate pressure distribution measurement system (PDM-S) with Foot Print software was used for these measurements.

Results: The cluster analysis revealed four groups: cluster $1(\mathrm{n}=19 ; 42.22 \%)$; cluster $2(\mathrm{n}=7$; $15.56 \%)$; cluster 3 ( $n=9 ; 20.00 \%)$; and cluster 4 ( $n=10 ; 22.22 \%)$.

Conclusion: Based on the MT parameters (extracted using a data reduction technique), two postural patterns were described: 1) the pro-gravitational postural pattern; and 2) the antigravitational pattern.

Keywords: deviation of body posture, strategy of compensation, moiré topography examinations, cluster analysis

\section{Introduction}

Children with cerebral palsy (CP) may show atypical body posture patterns, which may be the effect of functional strategies to compensate for an abnormal capacity to modulate subtle postural activity. ${ }^{1-4}$ These abnormal postural patterns are commonly the result of two interacting mechanisms: a primary deficit caused by early brain damage and a subsequent compensation caused by postural instability. Some studies have indicated that disorders of body posture in children with CP do not necessarily arise from impairments of the posture control system itself, but could be the effect of other unique pathophysiological factors, including neurological components (paresis and paralysis) or peripheral compensatory components..$^{5-8}$

Some research suggests that, although children with CP have an intact basic level of postural control, they demonstrate inadequacies in the fine-tuning of motor activity; $;, 7,9$ however, results of other studies indicate that $\mathrm{CP}$ is associated with poor timing of muscle response (greater latencies); failure to utilize appropriate control strategies in recovery (decreased use of ankle strategies, increased use of on-toes posturing); disordered muscle activation sequences; an inability to enhance the amplitude of
Correspondence: Małgorzata

Domagalska-Szopa

School of Health Sciences, Medical

University of Silesia, Medyków I2,

40-752 Katowice, Poland

Tel +4832 20887 I 2

Fax +48322088712

Email mdomagalska@sum.edu.pl
Therapeutics and Clinical Risk Management 20 I4: I0 I I3-120 
muscle response when balance is threatened; and inflexible co-contraction of agonist and antagonist muscles. ${ }^{10-14}$ Furthermore, children with CP tend to have impaired coordination of movement, reduced between-limb synchronization, and less weight-bearing on the affected side, which in turn can cause problems with maintaining upright weight-bearing position and gait. 8,9

In a previous study, which presented a descriptive analysis of abnormal postural patterns in children with hemiplegic $\mathrm{CP}$, a few different strategies for maintaining upright standing posture were observed. ${ }^{15}$ Continuing the observation in the previous study, we reported body posture asymmetry differences between children with mild scoliosis and children with hemiplegia. ${ }^{16}$ Based on the results of both previous studies, we hypothesized that children with unilateral CP present different body posture patterns.

Moiré topography (MT), a simple technique for threedimensional (3D) quantitation, has been used to provide interference photographs of the human back with sufficient accuracy to be used for describing body posture. ${ }^{17-21}$ The moiré phenomenon is caused by the appearance of shadows produced by light shining through a screen of thin, parallel strings. Its use in measuring deformity of the body surface was introduced by Takasaki in $1970 .{ }^{18}$ The currently used methods are based on computerized image-capturing and are digitally calculated. ${ }^{21}$ The surface topography software provides $3 \mathrm{D}$ viewing from arbitrary viewpoints, thus facilitating both quantitative 3D information and interactive exploratory analysis of the 3D shape of the back. For MT examination, it is necessary to mark particular anatomical landmarks. The Society on Scoliosis Orthopedic and Rehabilitation Treatment (SOSORT) Consensus and Statement and Guidelines suggest ten such points (Figure 1A). ${ }^{22}$

Based on these SOSORT points, many indices are created, which are computed in each of three planes and give objective (measurable) values of human body posture. The coronal plane is the major plane for measuring back deformity, since it is related to Cobb angle. Since Cobb angle can be obtained only with X-ray measurements, back surface indices were created to simulate the Cobb angle. ${ }^{22}$ Such indices include: spinous process line inclination (SP); angle of vertebral lateral curvature (ALC); shoulder line inclination; pelvic line inclination (PL); and Posterior Trunk Symmetry Index. The transverse plane is the second major plane for measuring back deformity. The major indices used with reference to this plane are the angles of rotation, such as: angle of trunk rotation; angle of shoulder rotation (SHR); and angle of pelvic rotation. The sagittal plane is the least-used plane regarding to back deformity. There exist few indices that are computed in this plane. Indices measured on the sagittal plane refer to the location and magnitude of the maximum kyphosis and lordosis.

The good repeatability of MT examination was reported by Chowańska et al in $2012 .{ }^{17}$ The study of Ruggerone and Austin ${ }^{19}$ reported high correlation between moiré angle analysis and radiographic analysis of spinal curvature, confirming the results of a previous study by Benoni and Willner. ${ }^{20}$

The purpose of the present study was to define different postural patterns in children with unilateral CP, using MT parameters.

\section{Materials and methods}

The Silesian Medical University Bioethics Committee, Katowice, Poland approved this study. All parents/guardians of participants gave written informed consent before data collection began.

\section{Subjects}

Forty-five outpatients with unilateral CP (17 girls and 28 boys) and deficits on the right side (29 patients) or left side (16 patients) were included in the study. The mean patient age was 9 years and 5 months (range: 7 years, 4 months to 12 years, 2 months). All participants were independently functioning outpatients (levels I or II on the Gross Motor Function Classification System) ${ }^{23}$ at local pediatric rehabilitation centers. The following selection criteria were applied: diagnosis of unilateral CP (hemiplegia); older than 7 years of age; able to stand without assistive devices; level I or II on the Gross Motor Function Classification System and no previous surgical procedures. The exclusion criteria were previous orthopedic surgery or dislocation of the hip.

\section{Methods}

Our study consisted of two interrelated parts:

1. MT examination; and

2. pedobarographic measurements of the distribution of body mass between the body sides.

\section{Testing procedure}

\section{MT examination}

Two of the authors, experienced physical therapists, performed MT examination using a CQ Elektronik System (Czernica, Poland) device. For the MT examination, it was necessary to uncover the whole surface of the back and to mark the anatomical landmarks (see Figure 1). MT was performed while the child stood quietly with open eyes. During the examination, 


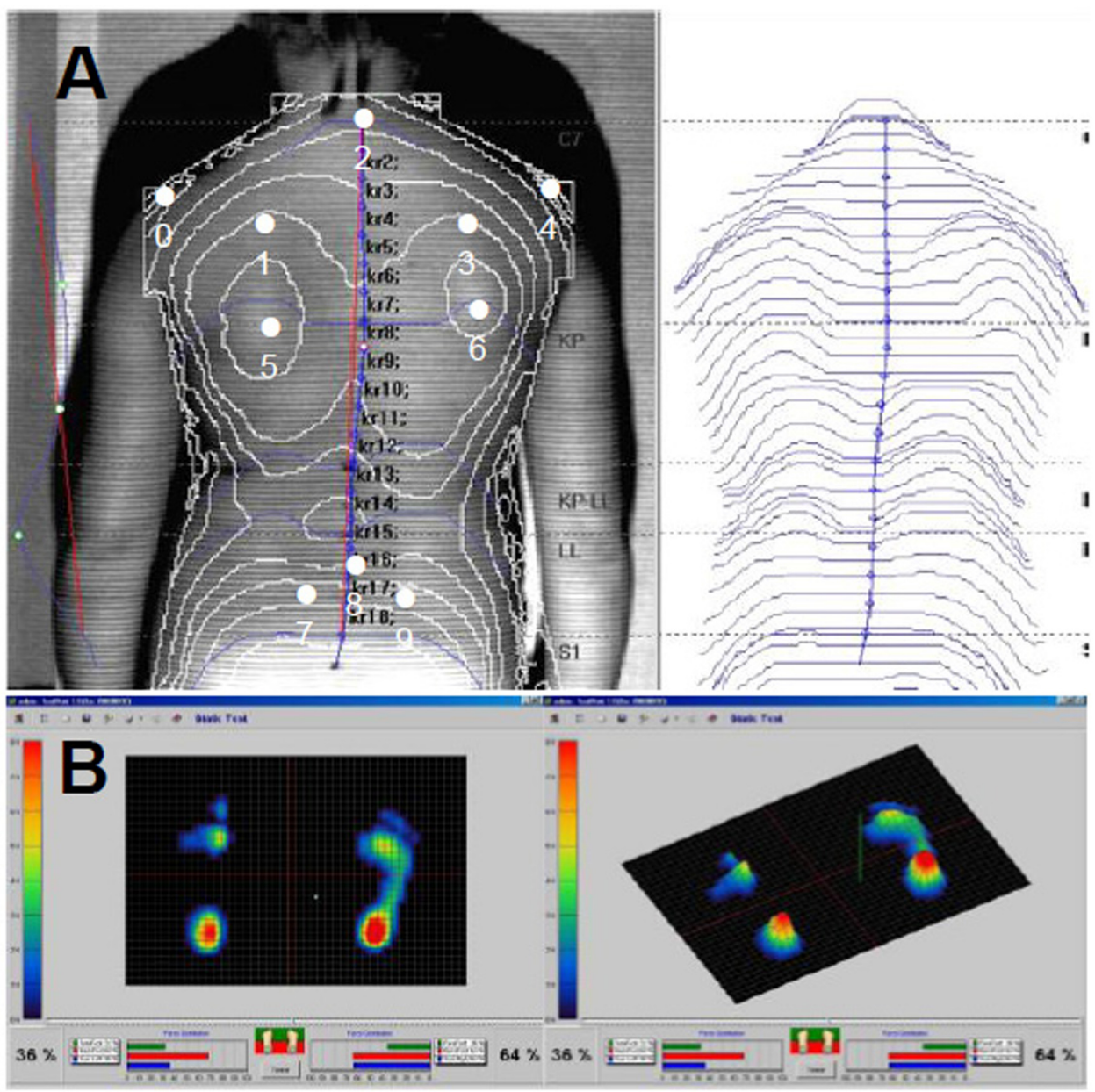

Figure I Moiré topography examination and pedobarographic measurements of the distribution of body mass between the body sides.

Notes: (A) Example of complex moiré fringe image of the subject's back. Anatomic landmarks used for back surface measurements were those suggested by the Society on Scoliosis Orthopedic and Rehabilitation Treatment (SOSORT). ${ }^{22}$ 2: Spinous process of C7; 8: spinous process of L4, 0, 4: acromial angle of shoulders; I, 3: superior angle of scapulae; 5, 6: inferior angle of scapulae; 7, 9: posterior superior iliac spine. (B) Examples of graphical representation of weight distribution in percentage between the unaffected and affected body sides while in quiet standing condition.

Abbreviations: C7, seventh cervical vertebra; L4, fourth lumbar vertebra.

the light was turned off, and the projection angle was $90^{\circ}$, which meant that the camera was placed perpendicular to the measured surface. Forty-millisecond images of the back were captured with a charge-coupled device camera. The recording of a sequence of images required 5 to 15 seconds per image (Figure 1). The image that was most characteristic of the child was chosen for further analysis by each expert. The arithmetic mean of their assessments was recorded. The accuracy of their evaluations was then analyzed. The analysis of moiré topograms began from calculating MT indices in each of the three planes (Table 1). All these values were automatically registered with the dedicated CQ-PlecyUSB software.

\section{Pedobarographic measurements}

In addition, an analysis of the weight distribution on the base of support between the affected and unaffected body sides was conducted simultaneously (Figure 1). A force plate pressure distribution measurement system PDM-S (zebris Medical GmbH, Isny, Germany) with Foot Print version 1.0 software was applied to obtain these types of pedobarographic measurements. Each measurement was recorded three times (three trials, each lasting for 30 seconds with a 30 -second pause between trials), and the average value for the calculation of the asymmetry index (AI) was used for further analysis.

\section{Statistical analysis}

Based on the AI (differences of weight distribution on the unaffected/affected body sides), one subgroup of symmetrical weight-bearing hemiplegics ( $\mathrm{AI}<10 \%$ ) and four subgroups of asymmetrical weight-bearing ( $\mathrm{AI} \geq 10 \%$ or $\mathrm{AI}>10 \%$ ) hemiplegics were created. The latter were: 
Table I Definitions of the outcome measures collected from MT examination

\begin{tabular}{|c|c|c|}
\hline MT index & Definition & Measurement \\
\hline ALC & $\begin{array}{l}\text { The angle of inclination contained between two } \\
\text { adjacent lines: a line situated within the sagittal plane } \\
\text { and a line of spinous processes from C7 through SI. } \\
\text { The angle of vertebral lateral curvature. }\end{array}$ & $\begin{array}{l}\text { If the line of spinous processes or apex of the lateral curve is on the right } \\
\text { side of the vertical line, the value of } S P \text { and } A L C \text { ranges from } 0^{\circ} \text { to } 180^{\circ} \text {. } \\
\text { If the } S P \text { or apex of the lateral curve is on the left side of the vertical line, } \\
\text { the index value ranges from }-180^{\circ} \text { to } 0^{\circ} \text {. }\end{array}$ \\
\hline SHL & $\begin{array}{l}\text { The angle of inclination contained between two } \\
\text { adjacent lines: a line situated within the sagittal } \\
\text { plane and a line connecting bilateral AAOS. }\end{array}$ & $\begin{array}{l}\text { The angle of inclination is contained between two adjacent lines: a line } \\
\text { situated within the horizontal plane and a line connecting the SAOS and } \\
\text { the PSIS lying on the back surface. This line is situated symmetrically on the }\end{array}$ \\
\hline $\mathrm{PL}$ & $\begin{array}{l}\text { The angle of inclination contained between two } \\
\text { adjacent lines: a line situated within the sagittal } \\
\text { plane and a line connecting bilateral PSIS. }\end{array}$ & $\begin{array}{l}\text { left and right sides; the angle has a value ranging from }-180^{\circ} \text { to } 0^{\circ} \text { when } \\
\text { the right AAOS or PSIS is higher than that of the left or from } 0^{\circ} \text { to } 180^{\circ} \\
\text { when the left AAOS or PSIS is higher than that of the right. }\end{array}$ \\
\hline $\mathrm{D}_{\max }$ & $\begin{array}{l}\text { The maximum of the horizontal distances measured } \\
\text { from the vertical line to the SP }(\mathrm{mm}) \text {. }\end{array}$ & $\begin{array}{l}\text { The angle of surface rotation is contained between two adjacent lines: a } \\
\text { line situated within the frontal plane and a line that connects two points on }\end{array}$ \\
\hline ATR & The angle of trunk rotation. & the back surface, and is situated symmetrically on the left and right sides \\
\hline SHR & The angle of shoulder rotation. & of the bilateral IAOS, AAOS, or the PSIS. The angle of rotation values \\
\hline PR & The angle of pelvic rotation. & $\begin{array}{l}\text { range from } 0^{\circ} \text { to } 180^{\circ} \text { if the right IAOS, AAOS, or the PSIS are rotated far } \\
\text { forward and ranges from }-180^{\circ} \text { to } 0^{\circ} \text { in the opposite case. }\end{array}$ \\
\hline $\begin{array}{l}\mathrm{K}_{\max } \\
\mathrm{L}_{\max }\end{array}$ & $\begin{array}{l}\text { The magnitude of the maximum kyphosis }(\mathrm{mm}) \text {. } \\
\text { The magnitude of the maximum lordosis }(\mathrm{mm}) \text {. }\end{array}$ & $\begin{array}{l}\text { These indices refer to the location and the magnitude of the maximum } \\
\text { kyphosis and lordosis. }\end{array}$ \\
\hline
\end{tabular}

Abbreviations: AAOS, acromial angle of the shoulders; ALC, angle of vertebral lateral curvature; ATR, angle of trunk rotation; C7, seventh cervical vertebra; $D_{\text {max }}$ maximum of the horizontal distances measured from the vertical line to the SP $(\mathrm{mm})$; IAOS, inferior angle of the scapula; $K_{\max }$, magnitude of maximum kyphosis; $L_{\text {max }}$, magnitude of maximum lordosis; MT, moiré topography; PL, pelvic line inclination; PR, angle of pelvic rotation; PSIS, posterior superior iliac spine; SI, first sacral vertebra; SAOS, superior angle of the scapula; SHL, shoulder line inclination; SHR, angle of shoulder rotation; SP, spinous process line inclination.

- left side hemiplegic with tendency to overload the affected body side (LL);

- right side hemiplegic with tendency to overload the affected body side (RR);

- left side hemiplegic with tendency to overload the unaffected body side (LR); and

- right side hemiplegic with tendency to overload the unaffected body side (RL).

Ten MT examination parameters were originally defined for each subject. Because of the high dimensionality of the postural analysis data and the parameter correlations, a data reduction technique, factor analysis (six factors extracted), was used as the input for the nonhierarchical k-means clustering. ${ }^{24}$ Four clusters were defined. The mean and standard deviation (SD) of each parameter was calculated for the total group and for each of the four clusters. All data were compared between subgroups. An analysis of variance (Tukey's post hoc test) was used to detect the differences in the MT examination parameters between the four clusters. Only differences that were significant $(P<0.05)$ between the clusters were described and discussed.

Intraclass correlation coefficient with $95 \%$ confidence interval was used to measure overall intra- and interobserver agreement. Interobserver agreement was calculated separately for each MT and pedobarographic measurement parameter, based on two examinations, performed by the same two researchers, of ten subjects (20 examinations in total); interobserver agreement was calculated. For the analysis, mean intraclass correlation coefficient values of 0.80 and above reflected excellent reliability; those between 0.70 and 0.79 indicated good reliability; and those below 0.70 reflected poor-to-moderate reliability.

\section{Results}

AI of weight distribution between the unaffected and affected body side in each participant was calculated. ${ }^{16} \mathrm{AI}$ was, on average, $6.96 \% \pm 28.48 \%$ (range: $-38 \%$ to $46 \%$ ). The data for the asymmetrical weight-bearing subgroups were as follows:

- RL: $n=16(36 \%)$;

- LL: $\mathrm{n}=10(22 \%)$;

- RR: $n=13(29 \%)$; and

- LR: $\mathrm{n}=6(13 \%)$.

Using a data reduction technique, four grouping variables were extracted: SP, PL, shoulder line inclination, and ALC. According to the cluster analyses results, 19 (42.22\%) participants were classified in cluster 1 , while seven $(15.56 \%)$ were included in cluster 2 ; nine $(20.00 \%)$ in cluster 3 ; and ten $(22.22 \%)$ in cluster 4 (Table 2). There appeared to be some major differences between the means of the various clusters for each variable, which are shown in Table 3. Table 4 shows the $F$-values and significance levels, and that all mean differences are significant.

In our cohort of children with unilateral $\mathrm{CP}$, we identified four clusters (Table 2):

- cluster 1 was predominantly characterized by subgroup $\mathrm{RL}$ ( $\mathrm{n}=14$ from a total of 16 subjects); 
Table 2 Nonhierarchical k-means clustering

\begin{tabular}{clllll}
\hline Subgroup & Cluster I & Cluster 2 & Cluster 3 & Cluster 4 & Total \\
\hline RR & & & & & \\
$\mathrm{N}$ & 0 & 0 & 9 & 4 & 13 \\
$\%$ & 0.00 & 0.00 & 100.00 & 40.00 & 28.89 \\
$\mathrm{RL}$ & & & & & \\
$\mathrm{N}$ & 14 & 2 & 0 & 0 & 16 \\
$\%$ & 73.68 & 28.57 & 0.00 & 0.00 & 35.56 \\
LR & & & & & \\
$\mathrm{N}$ & 0 & 0 & 0 & 6 & 6 \\
$\%$ & 0.00 & 0.00 & 0.00 & 60.00 & 13.33 \\
LL & & & & & \\
$\mathrm{N}$ & 5 & 5 & 0 & 0 & 10 \\
$\%$ & 26.32 & 71.43 & 0.00 & 0.00 & 22.22 \\
Total & & & & & \\
$\mathrm{N}$ & 19 & 7 & 9 & 10 & 45 \\
$\%$ & 42.22 & 15.56 & 20.00 & 22.22 & 100.00 \\
\hline
\end{tabular}

Abbreviations: RR, right side hemiplegic with tendency to overload the affected body side; RL, right side hemiplegic with tendency to overload the unaffected body side; LR, left side hemiplegic with tendency to overload the unaffected body side; $\mathrm{LL}$, left side hemiplegic with tendency to overload the affected body side.

- cluster 2 was predominantly characterized by subgroup LL ( $\mathrm{n}=5$ from a total of ten subjects);

- cluster 3 was predominantly characterized by subgroup $\mathrm{RR}$ ( $\mathrm{n}=9$ from a total of 13 subjects); and

- cluster 4 was predominantly characterized by subgroup LR ( $\mathrm{n}=6$ from a total of six subjects).

Table 3 Parameter data

\begin{tabular}{|c|c|c|c|c|c|c|}
\hline $\begin{array}{l}\text { MT } \\
\text { index }\end{array}$ & Cluster & Mean & $\mathbf{N}$ & SD & Minimum & Maximum \\
\hline \multirow[t]{5}{*}{$\mathrm{SP}\left({ }^{\circ}\right)$} & 1 & -4.584 & 19 & 5.265 & -11.300 & 3.500 \\
\hline & 2 & $-3.67 \mid$ & 7 & 5.676 & -11.900 & 3.600 \\
\hline & 3 & 9.889 & 9 & 2.824 & 5.200 & 13.400 \\
\hline & 4 & 3.190 & 10 & 3.924 & -0.700 & 10.200 \\
\hline & Total & 0.180 & 45 & 7.337 & -11.900 & 13.400 \\
\hline \multirow[t]{5}{*}{$\operatorname{PL}\left({ }^{\circ}\right)$} & I & 9.300 & 19 & 4.266 & -0.700 & 14.300 \\
\hline & 2 & I.97I & 7 & $4.08 I$ & 2.100 & 13.100 \\
\hline & 3 & -6.300 & 9 & 7.045 & -13.800 & 10.600 \\
\hline & 4 & -9.930 & 10 & 3.293 & -13.900 & -4.100 \\
\hline & Total & 1.700 & 45 & 9.797 & -13.900 & 14.300 \\
\hline \multirow[t]{5}{*}{$\operatorname{SHR}\left({ }^{\circ}\right)$} & 1 & -11.089 & 19 & 10.354 & -31.000 & 2.200 \\
\hline & 2 & 3.529 & 7 & 10.713 & -16.600 & 15.900 \\
\hline & 3 & 4.167 & 9 & 3.957 & -0.700 & 10.600 \\
\hline & 4 & 8.670 & 10 & 5.356 & 0.000 & 18.000 \\
\hline & Total & -1.373 & 45 & 11.917 & -31.000 & 18.000 \\
\hline \multirow[t]{5}{*}{$\operatorname{ALC}\left({ }^{\circ}\right)$} & I & 178.084 & 19 & 3.260 & 169.900 & 180.000 \\
\hline & 2 & 172.620 & 10 & 4.085 & 165.500 & 180.000 \\
\hline & 3 & $|60.31|$ & 9 & 5.396 & 152.700 & 167.600 \\
\hline & 4 & 173.157 & 7 & 5.887 & 162.800 & 180.000 \\
\hline & Total & I 72.549 & 45 & 7.855 & | 52.700 & 180.000 \\
\hline
\end{tabular}

Note: Bold font indicate cluster 2 and 3 , which represent PGPP; while cluster I and 4 (not bold) represent AGPP.

Abbreviations: ALC, angle of vertebral lateral curvature; MT, moiré topography; $\mathrm{PL}$, pelvic line inclination; SD, standard deviation; SHR, angle of shoulder rotation; $\mathrm{SP}$, spinous process line inclination.
Table 4 Differences between the means of the various MT parameter clusters (ANOVA)

\begin{tabular}{lllllll}
\hline $\begin{array}{l}\text { MT } \\
\text { index }\end{array}$ & Comparison & $\begin{array}{l}\text { Sum of } \\
\text { squares }\end{array}$ & df & $\begin{array}{l}\text { Mean } \\
\text { square }\end{array}$ & $\boldsymbol{F}$ & $\boldsymbol{P}$ \\
\hline SP $\left(^{\circ}\right)$ & Between groups & $1,474.055$ & 3 & 21.822 & 22.517 & 0.001 \\
& Within groups & 491.352 & 41 & & & \\
& Total & 894.657 & 44 & & & \\
PL $\left(^{\circ}\right)$ & Between groups & $3,301.325$ & 3 & 22.489 & 48.932 & 0.001 \\
& Within groups & $1,100.442$ & 41 & & & \\
& Total & 922.055 & 44 & & & \\
SHR $\left(^{\circ}\right)$ & Between groups & $3,246.775$ & 3 & 73.216 & 14.782 & 0.001 \\
& Within groups & $1,082.200$ & 41 & & & \\
& Total & $3,001.853$ & 44 & & & \\
ALC $\left(^{\circ}\right)$ & Between groups & $1,046.310$ & 3 & 23.798 & 14.655 & 0.001 \\
& Within groups & 348.770 & 41 & & & \\
& Total & 975.738 & 44 & & & \\
\hline
\end{tabular}

Abbreviations: ALC, angle of vertebral lateral curvature; ANOVA, analysis of variance; df, degrees of freedom; MT, moiré topography; PL, pelvic line inclination; SHR, angle of shoulder rotation; SP, spinous process line inclination.

Clusters 2 and 3 were characterized by postural patterns with a tendency toward weight-bearing on the affected body sides, while clusters 1 and 4 were characterized by postural patterns with a tendency to overload the unaffected body sides (Table 2). All four clusters presented characteristic spatial relations of the shoulder rotation, pelvic inclination, and type of scoliosis. Clusters 1 and 4 were defined by the following characteristics:

- SP: spine inclination on the unaffected side;

- PL: pelvis obliquity up on the affected side; and

- SHR: shoulder external rotation on the affected side.

Clusters 2 and 3 were defined by the following factors:

- SP: spine inclination on the affected side;

- PL: pelvis obliquity down on the affected side; and

- SHR: shoulder internal rotation on the affected side.

Tukey's post hoc tests revealed that the ALCs were statistically significantly larger in clusters 1 and 4 versus clusters 2 and 3 , while there were no significant differences between clusters 1 and 4, and between clusters 2 and 3 .

Based on the aforementioned relationships, two types of compensatory postural patterns in children with unilateral $\mathrm{CP}$ were defined:

- the anti-gravitational compensatory postural pattern (AGPP), characterized by cluster 1 and cluster 4 together; and

- the pro-gravitational compensatory postural pattern (PGPP), characterized by cluster 2 and cluster 3 together. 


\section{Discussion}

This study confirmed that, despite the apparent similarities in children with unilateral $\mathrm{CP}$, their postural patterns do differ. The cluster analysis showed that two basic postural patterns (PGPP and AGPP) are present in children with unilateral CP. The differences between PGPP and AGPP included not only the characteristic weight-bearing on the unaffected or affected body sides, but also clear differences in spine, pelvis, and shoulder girdle orientation. In the AGPP children, the pelvis expressed obliquity up on the affected side, while, in the PGPP children, the opposite pattern (ie, pelvis obliquity down) was present. Two opposing patterns were noted in the shoulder girdle rotation, as well. External rotation (backward on the affected side) was more typical for the AGPP children, and internal rotation (forward on the affected side) was more typical for PGPP children. In most (84\%) of the examined children, lateral spinal curvature was noted. All children with AGPP showed convexity towards the unaffected side, while, in the children with PGPP, this was toward the affected side. Importantly, in children with AGPP, the affected side was the under-loaded side, while, in children with PGPP, it was the overloaded side. Additionally, we observed that S-type curvature was more characteristic in the children expressing PGPP (76\%), while C-type scoliosis predominated in the AGPP children (67\%). Moreover, the observed in PGPP $\mathrm{S}$-scoliosis have far greater values of lateral curvature angle than analogical C- scoliosis in AGPP. This finding proves that overloading of the affected body side in children presenting PGPP can be a serious risk factor for asymmetry and scoliosis progression. In more severe deformations related to scoliosis, decreasing of lung capacity and decreased pulmonary efficiency can occur. On the other hand, for children with the AGPP characteristic, the pelvic hike was on the affected side (hemipelvis up) and there was excessive ankle plantar flexion (equines). These can be caused by an impaired body image, gastrocnemius spasticity/contracture, or pathological synergistic activity. Excessive plantar flexion can be a reason for some gait errors, such as toe-walking or inadequate dorsiflexion for the foot in swing. Our findings suggest that postural pattern can not only cause gait disturbances, but also affect walking energy consumption in different ways in children with AGPP and PGPP. The postural pathology characteristic of all children with hemiplegia should be addressed, as it influences the overall functional efficacy of these patients.

To our knowledge, this study is the first examination of body posture in a cohort of children with unilateral $\mathrm{CP}$, based on the measurable surface topography method including
MT measurement. Dividing participants into four subgroups based on the hemiplegic side and tendency to overload the unaffected or affected body side was an important outcome goal of our analyses. In calculation of MT indices, plus $(+)$ and minus ( - ) are used to characterize the indices in terms of direction of inclination or rotation (see SP, ALC, SHR, and PL). Therefore, the average of indices of children with left and right hemiplegia and tendency to overload the affected body side did not show any real value of disturbance because the average from positive and negative values can be zero and indicates the lack of disturbances. It can be the same in cases of children with left and right hemiplegia and tendency to overload the unaffected body side. Therefore four (rather than two) clusters defined for the cluster analysis, what was an important point of presented analyses because the values of indices depend on both hemiplegic side, and weight-bearing on the unaffected or affected body sides. The breakdown of the material for four subgroups also strongly modified the results of the analyses. We demonstrated that there is a potential danger in using surrogate measures as the only or primary outcome measure in body posture analysis in children with CP. The weight-bearing measures and MT indices may be of limited value in children with CP when used separately.

Although many studies report postural problems in children with $\mathrm{CP}$ who can stand and walk, including postural dysfunction in the adjustment adaptation; ${ }^{8,25}$ problems with postural control when standing, walking, or running; ${ }^{26,27}$ and anticipatory and compensatory postural adjustments when sitting or standing, ${ }^{26,28,29}$ there have been no reports by other authors of body posture examination in children with hemiplegia. For this reason, we cannot present our results in relationship to other studies.

This study offers some evidence that two different postural patterns may exist among hemiplegic children and that each of these can cause different additional functional problems. An understanding of this could help all specialists involved in postural management to predict the types and degrees of postural disturbance before they become established. This, in turn, will facilitate earlier intervention aimed at counteracting the asymmetrical postural deformities. Knowledge of the AGPP and PGPP patterns can be helpful when making decisions during early therapy, including deciding which of the mechanisms of postural compensation must be activated, which mechanisms must be facilitated, which mechanisms must be modified, and, finally, which mechanisms must be inhibited. Scientific evidence of the benefits of body posture analysis in children with CP remains, however, insufficient and follow-up studies are required. 


\section{Conclusion}

The present study shows that, despite apparent similarities, postural patterns in children with unilateral $\mathrm{CP}$ differ. Based on the presented findings, we identified and defined two compensatory postural patterns in children with unilateral CP: AGPP and PGPP. Additionally, we described the basic differences between AGPP and PGPP, which can be used to develop guidelines for the differentiation, management, and treatment of children with unilateral CP.

Because the results of the current study are promising, these findings will be further explored in another series of studies. In these upcoming studies, we will explore motor skill and functional efficiency (eg, example gait patterns, walking energy consumption, and pulmonary efficiency) differences between hemiplegic children with AGPP and PGPP.

\section{Author contributions}

MDS and AS both participated in the concept and design of the study. Both authors performed the experiments, analyzed and interpreted the data, and wrote this paper. Both authors read and approved the final manuscript.

\section{Disclosure}

The authors report no conflicts of interest in this work.

\section{References}

1. Assaiante C, Woollacott M, Amblard B. Development of postural adjustment during gait initiation: kinematic and EMG analysis. J Mot Behav. 2000;32(3):211-226.

2. Brenière Y, Bril B. Development of postural control of gravity forces in children during the first 5 years of walking. Exp Brain Res. 1998;121(3): 255-262.

3. Hadders-Algra M, Brogen E, Forssberg H. Ontogeny of postural adjustments during sitting in infancy: variation, selection and modulation. J Physiol. 1996;493(Pt 1):273-288.

4. Malouin F, Richards CL. Preparatory adjustments during gait initiation in 4-6-year-old children. Gait Posture. 2000;11(3):239-253.

5. Carlberg EB, Hadders-Algra M. Postural dysfunction in children with cerebral palsy: some implications for therapeutic guidance. Neural Plast. 2005;12(2-3):221-228.

6. Graham HK. Mechanisms of deformity. In: Scrutton D, Mayston M, editors. Management of the Motor Disorders of Children with Cerebral Palsy. London: Mac Keith Press; 2004:105-129.

7. van der Heide JC, Hadders-Algra M. Postural muscle dyscoordination in children with cerebral palsy. Neural Plast. 2005;12(2-3):197-203.

8. Woollacott MH, Shumway-Cook A. Postural dysfunction during standing and walking in children with cerebral palsy: what are the underlying problems and what new therapies might improve balance? Neural Plast. 2005;12(2-3):211-219.

9. Bax M, Goldstein M, Rosenbaum P, et al. Executive Committee for the Definition of Cerebral Palsy. Proposed definition and classification of cerebral palsy, April 2005. Dev Med Child Neurol. 2005;47(8):571-576
10. Hadders-Algra M, Carlberg EB, editors. Postural control in sitting children with cerebral palsy. In: Postural Control: A Key Issue in Developmental Disorders. London: Mac Keith Press; 2008:74-96.

11. Burtner PA, Qualls C, Woollacott MH. Muscle activation characteristics of stance balance in children with spastic cerebral palsy. Gait Posture. 1998;8:163-174.

12. Liu W, Zaino C, Westcott S. Anticipatory postural adjustments in children with cerebral palsy and children with typical development during functional reaching: a center of pressure study. Pediatr Phys Ther. 2000;12(4):218-219.

13. Roncesvalles MN, Woollacott MW, Burtner PA. Neural factors underlying reduced postural adaptability in children with cerebral palsy. Neuroreport. 2002;13:2407-2410.

14. Shumway-Cook A, Hutchinson S, Kartin D, Price R, Woollacott M. Effect of balance training on recovery of stability in children with cerebral palsy. Dev Med Child Neurol. 2003;45:591-602.

15. Domagalska ME, Szopa AJ, Lembert DT. A descriptive analysis of abnormal postural patterns in children with hemiplegic cerebral palsy. Med Sci Monit. 2011;17(2):CR110-CR116

16. Domagalska-Szopa M, Szopa A. Body posture asymmetry differences between children with mild scoliosis and children with unilateral cerebral palsy. Biomed Res Int. 2013;2013:462094.

17. Chowanska J, Kotwicki T, Rosadzinski K, Sliwinski Z. School screening for scoliosis: can surface topography replace examination with scoliometer? Scoliosis. 2012;7(1):9.

18. Takasaki H. Moiré topography. Appl Opt. 1970;9:1467-1472.

19. Ruggerone M, Austin JH. Moiré topography in scoliosis. Correlations with vertebral lateral curvature as determined by radiography. Phys Ther. 1986;66(7):1072-1077.

20. Benoni G, Willner S. Asymmetry of moire pattern in scoliosis at different levels of the spine. In: Drerup B, editor. Moire Fringe Topography and Spinal Deformity. Stuttgart: Gustav Fisher Verlag; 1983:93-98.

21. Suzuki N, Armstrong GWD, Armstrong J.Application of moiré topography to spinal deformity. In: Moreland MS, Pope MH, Armstrong GWD, editors. Moiré Fringe Topography and Spinal Deformity: Proceedings of an International Symposium. Oxford, Toronto; Pergamon Press; 1981:225-240.

22. Grivas TB, Wade MH, Negrini S, et al. SOSORT consensus paper: school screening for scoliosis. Where are we today? Scoliosis. 2007;2:17.

23. Palisano R, Rosenbaum P, Walter S, Russell D, Wood E, Galappi B. Development and reliability of a system to classify gross motor function in children with cerebral palsy. Dev Med Child Neurol. 1997;39:214-223.

24. Davidson I. Understanding K-Means Non-Hierarchical Clustering. Albany, NY: SUNY; 2002. Available from http://citeseerx.ist.psu. edu/viewdoc/download?doi=10.1.1.120.2319\&rep=rep1\&type=pdf. Accessed January 31, 2014.

25. Hodgkinson I, Bérard C, Chotel F, Bérard J. [Pelvic obliquity and scoliosis in non-ambulatory patients with cerebral palsy: a descriptive study of 234 patients over 15 years of age]. Rev Chir Orthop Reparatrice Appar Mot. 2002;88(4):337-341. French.

26. Bigongiari A, de Andrade e Souza F, Franciulli PM, Neto Sel R, Araujo RC, Mochizuki L. Anticipatory and compensatory postural adjustments in sitting in children with cerebral palsy. Hum Mov Sci. 2011;30(3):648-657.

27. Böhm H, Döderlein L. Gait asymmetries in children with cerebral palsy: do they deteriorate with running? Gait Posture. 2012;35(2):322-327.

28. Ferdjallah M, Harris GF, Smith P, Wertsch JJ. Analysis of postural control synergies during quiet standing in healthy children and children with cerebral pals. Clin Biomech (Bristol, Avon). 2002;17(3):203-210.

29. Rose J, Wolff DR, Jones VK, Bloch DA, Oehlert JW, Gamble JG. Postural balance in children with cerebral palsy. Dev Med Child Neurol. 2002;44(1):58-63. 


\section{Publish your work in this journal}

Therapeutics and Clinical Risk Management is an international, peerreviewed journal of clinical therapeutics and risk management, focusing on concise rapid reporting of clinical studies in all therapeutic areas, outcomes, safety, and programs for the effective, safe, and sustained use of medicines. This journal is indexed on PubMed Central, CAS,

EMBase, Scopus and the Elsevier Bibliographic databases. The manuscript management system is completely online and includes a very quick and fair peer-review system, which is all easy to use. Visit http://www.dovepress.com/testimonials.php to read real quotes from published authors.

Submit your manuscript here: http://www.dovepress.com/therapeutics-and-clinical-risk-management-journal 